\title{
A narrative review of multiple mechanisms of progranulin in cancer: a potential target for anti-cancer therapy
}

\author{
Chenhui Zhou ${ }^{1}$, Yi Huang ${ }^{1}$, Jingmi Wu$^{1}$, Yiting Wei ${ }^{1}$, Xiaosheng Chen ${ }^{2}$, Zhiqing Lin $^{1}$, Sheng Nie ${ }^{1}$ \\ ${ }^{1}$ Department of Neurosurgery, Ningbo First Hospital, Ningbo Hospital, Zhejiang University School of Medicine, Ningbo, China; ${ }^{2}$ Department of \\ Neurosurgery, Ningbo First Hospital, Ningbo University School of Medicine, Ningbo, China \\ Contributions: (I) Conception and design: C Zhou; (II) Administrative support: Z Lin, S Nie; (III) Provision of study materials or patients: C Zhou, J \\ Wu; (IV) Collection and assembly of data: Y Huang; (V) Data analysis and interpretation: Y Wei, X Chen; (VI) Manuscript writing: All authors; (VII) \\ Final approval of manuscript: All authors. \\ Correspondence to: Sheng Nie. Department of Neurosurgery, Ningbo First Hospital, Ningbo Hospital, Zhejiang University School of Medicine, No. \\ 59 Liuting Street, Ningbo 315010, China. Email: niesheng1981@163.com.
}

\begin{abstract}
Progranulin (PGRN) is an autocrine growth factor and has important effects on regulation of cell growth, motility, tissue repair and embryonic development. Recent years, several researches found the expression of PGRN was at higher levels in a number of cancer cells and its high levels are associated with poor outcome of patients. More and more studies investigated the role of PGRN in cancer and found PGRN exerted various biological functions in cancer cells, such as promoting proliferation, inhibiting apoptosis, inducing migration and invasion of cells, accelerating angiogenesis and enhancing the effectiveness of chemoresistance and radiation. Now the effects of PGRN have been demonstrated in several cancers, including breast cancer, lung cancer, and bladder cancer. In addition, several signaling pathways and molecules are involved in the effects of PGRN on cancer cells, including Akt, mitogen-activated protein kinase (MAPK), vascular endothelial growth factor (VEGF) and cyclin D1. Therefore, PGRN is probably a significant diagnostic and prognostic biomarker for cancer and may be a potential target for anti-cancer therapy. Here, we reviewed the advancing field of PGRN in cancer as well as several signaling pathways activated by PGRN and confirmed PGRN is a key role in cancer. Moreover, future studies are still necessary to elucidate the biological functions and signaling pathways of PGRN in cancer.
\end{abstract}

Keywords: Cancer; molecular targets; progranulin (PGRN)

Submitted Oct 01, 2020. Accepted for publication Jul 30, 2021.

doi: $10.21037 /$ tcr-20-2972

View this article at: https://dx.doi.org/10.21037/tcr-20-2972

\section{Introduction}

Progranulin (PGRN), also known as proepithelin, granulinepithelin precursor, or acrogranin, is a growth factor that is ubiquitously expressed throughout the body $(1,2)$. PGRN has various biological functions such as regulation of cell growth and motility, tissue repair, and embryonic development $(3,4)$. The effects of PGRN include wound healing, brain injury, and cancer progression $(2,5)$. Studies have shown that PGRN plays a role in multiple cancers including leukemia, breast cancer, ovarian cancer, and glioblastoma. PGRN is expressed at elevated levels in tumors (compared to normal controls), and increased PGRN level is associated with increased tumorigenicity and drug resistance, and a poor prognosis (6,7). PGRN exerts multiple effects on cancer progression including promoting proliferation, stimulating migration and invasion, and

\footnotetext{
^ ORCID: 0000-0003-1369-1245.
} 
Table 1 Functions and molecular targets of PGRN in cancer

\begin{tabular}{|c|c|c|}
\hline Cancer & Functions & Molecular targets \\
\hline Lung cancer & Induces invasion and migration; induces chemotherapy resistance & VEGF \\
\hline $\begin{array}{l}\text { Hepatocellular } \\
\text { carcinoma }\end{array}$ & $\begin{array}{l}\text { Induces angiogenesis; promotes proliferation, invasion, and migration; } \\
\text { reduces chemosensitivity }\end{array}$ & VEGF, Akt, MAPK, mTOR \\
\hline Colorectal cancer & $\begin{array}{l}\text { Induces cancer growth, migration, and invasion; promotes angiogenesis } \\
\text { and activation of fibroblasts }\end{array}$ & TNFR2/Akt, ERK, Wnt \\
\hline Ovarian cancer (8) & $\begin{array}{l}\text { Promotes proliferation and motility of cancer cells; inhibits apoptosis; } \\
\text { induces migration and invasion }\end{array}$ & PKC, CDK4, cyclin D, MAPK, MMP-2 \\
\hline Glioma & Induces chemotherapy resistance; inhibits apoptosis & AP-1, PI3K/Akt, ERK1/2, CDK4/6/pRb \\
\hline Cervical cancer & Induces proliferation; inhibits senescence & PI3K/Akt/mTOR \\
\hline Endometrial cancer & Promotes proliferation, invasion, and metastasis; induces angiogenesis & VEGF \\
\hline Gastric cancer & Promotes proliferation and migration & Akt, MAPK, MEK1/2 \\
\hline Pancreatic cancer & Supports metastasis; stimulates proliferation & - \\
\hline Esophageal cancer & Promotes angiogenesis & VEGF \\
\hline Mesothelioma & Induces angiogenesis and tube formation & - \\
\hline
\end{tabular}

CDK4, cyclin dependent kinase 4; ERK, extracellular regulated protein kinases; MAPK, mitogen-activated protein kinase; MEK1/2, mitogen-activated protein kinase kinases 1 and 2; MMP-2, matrix metallopeptidase 2; mTOR, mammalian target of rapamycin; PGRN, TNF- $\alpha$, tumor necrosis factor- $\alpha$; PI3K, phosphatidylinositol-3-kinase.; PKC, protein kinase C; TNFR2, tumor necrosis factor receptor 2; VEGF, vascular endothelial growth factor.

mediating angiogenesis and resistance to apoptosis. In this review, we describe the latest progress of PGRN in cancer study (Table 1) $(8,9)$. We present the following article in accordance with the Narrative Review reporting checklist (available at https://dx.doi.org/10.21037/tcr-20-2972).

\section{Effects of PGRN on cancer progression}

\section{Promotes proliferation of cancer cells}

The rapid proliferation of cancer cells is a main characteristic of cancer progression and can promote migration and invasion $(10,11)$. Cancer cell proliferation is regulated by growth factors and several signaling pathways such as Akt and mitogen-activated protein kinase (MAPK) $(12,13)$. The processes of cancer cell proliferation and migration and invasion depend on rearrangement of the actin cytoskeleton (14), which is associated with the formation of new integrin substratum contacts and the release of preexisting cell matrix contacts (15). The effect of PGRN on the proliferation of cancer cells has been explored, and PGRN has emerged as a critical regulator of proliferation in several cancer types include prostate, colorectal, cervical, and ovarian cancers $(7,8,16)$. PGRN defines a cancer stem cell subpopulation and can enhance the colony-forming capability of tumor cells (17). In addition, several signaling 
pathways such as tumor necrosis factor receptor 2 (TNFR2)/ Akt, protein kinase $\mathrm{C}$, and MAPK are involved in the PGRN-mediated regulation of cancer cell proliferation $(7,18)$. Yang et al. (7) found that PGRN overexpression increased the expression of vascular endothelial growth factor A (VEGF-A) and promoted the growth of colorectal cancer cells. This regulation by PGRN was mediated by TNFR2/Akt and extracellular signal-regulated kinase (ERK) signaling pathways in both colorectal cancer and human umbilical vein endothelial cells (HUVECs). In addition, a previous study demonstrated that knockdown of PGRN caused a decrease in the growth of glioma cells (19). Therefore, because PGRN plays a clear role in promoting cancer cell proliferation, inhibiting PGRN may have antiproliferative effects (20).

\section{Resistance to apoptosis}

Apoptosis is the process of programmed cell death and comprises several events such as chromosomal DNA fragmentation, nuclear fragmentation, cellular blebbing, and ultimately cell death (21-23). Apoptosis occurs in many tissues and organs and takes place in a regulated process, conferring advantage during an organism's life cycle $(24,25)$. Therefore, accelerating apoptosis in tumor cells can diminish tumor burden $(26,27)$. The role of PGRN in apoptosis in cancer has been demonstrated (28). In cholangiocarcinoma, PGRN inhibits apoptosis, and knockdown of PGRN promotes apoptosis by increasing the ratio of $\mathrm{B}$-cell lymphoma 2 (Bcl-2) to Bcl-2-associated X protein (29). Studies have showed that anti-PGRN antibody can induce ovarian cancer cell apoptosis by regulating cleaved caspase-3, DNA fragmentation, nuclear condensation, and poly (ADP ribose) polymerase cleavage (30).

\section{Induces migration and invasion}

Migration and invasion are two important properties of cancer $(31,32)$, and are the most pivotal factors leading to cancer-associated mortality (33). Malignant cancer cells cross the basement membrane, escape from the primary tumor, and attach to the surrounding extracellular matrix (ECM) (34). Then cancer cells metastasize and invade the surrounding tissue. They break away from the original location and migrate to other organs and tissues of the body by direct extension or through the circulatory and lymphatic systems (35). Matrix metalloproteinases (MMPs) play an essential role in the migration and invasion of cancer cells (36). Swerlick et al. (37) found four membrane-type MMPs that were highly expressed in PGRN-stimulated cancer and PGRN treatment could elevate the transcription of specific matrix-degrading enzymes. In addition to MMPs, PGRN can active ERK1/2 and form a paxillin/focal adhesion kinase/ERK complex to promote migration and invasion in bladder cancer (9). In addition, Blood et al. (38) reported that PGRN is a key target for microRNA-588, leading to the suppression of migration and invasion in lung cancer. Thus, inhibiting PGRN may be valuable in preventing the migration and invasion of cancer cells.

\section{Mediates angiogenesis}

Angiogenesis is a process by which new vasculature is formed (37). Angiogenesis in physical condition is just transient (39), and sustained angiogenesis is observed during tumorigenesis (38). Tumor angiogenesis is essential for tumor progression and is always associated with an adverse prognosis (40). VEGF is a key angiogenic factor and is considered a pivotal target of tumor treatment (41). Anti-VEGF antibodies, such as bevacizumab, have been used as anti-angiogenic therapy for the treatment of several cancers and the therapeutic benefits are approved (42). The relationship between PGRN and angiogenesis has been established, and the effect of PGRN on promoting angiogenesis has been confirmed in various cancers. In addition, the high expression of PGRN is associated with elevated VEGF concentrations in tissue from breast cancer, colorectal cancer, and esophageal squamous cell carcinoma $(43,44)$. Previous studies found that recombinant PGRN not only increased the expression of VEGF in HUVECs but also directly activated the angiogenic characteristic of HUVECs, suggesting the direct and indirect effects of PGRN on tumor angiogenesis. The overexpression of VEGF induced by PGRN is through the TNFR2/Akt and ERK signaling pathways (7). In addition to targeting VEGF, the midkine protein/PGRN complex stimulates angiogenesis by another mechanism and the co-stimulatory effect is significantly increased. This complex promotes migration, proliferation, and tubular structure formation to mediate tumor angiogenesis (39). Therefore, therapies to neutralize the effect of PGRN are available as an antiangiogenic treatment strategy for cancers.

\section{Promote chemoresistance and radiation}

Chemotherapy is important for patients with cancer and is 
widely used for the treatment of unresectable cancer $(45,46)$. However, many types of cancer cells are resistant to anticancer drugs, which is a huge obstacle to chemotherapy (47). Chemoresistance observably affects the survival of patients with cancer, but the precise mechanism is still unknown. Several studies have indicated that growth factors may be involved in the mechanism of chemoresistance. PGRN, as a growth factor, is associated with chemoresistance in several cancer cells (48). In breast cancer, PGRN overexpression and cross-talk with the estrogen receptor are considered factors that cause chemoresistance $(49,50)$. PGRN also confers letrozole resistance by preventing the downregulation of Bcl-2 expression by letrozole in breast cancer (51). In addition, PGRN plays a crucial role in promoting glioblastoma chemoresistance by orchestrating DNA repair (19). In addition, PGRN has effects on radiation. Granulin (GRN) was upregulated in response to ionizing radiation in $\mathrm{PC}-3$ prostate cancer cells. On the other hand, miRNA-107 enhances radiosensitivity by suppressing GRN in these cells (52).

\section{Molecular targets of PGRN in cancer}

\section{Akt}

Akt is a key factor for the proliferation, progression, and metastasis of tumors, and its function has been demonstrated in several cancers such as breast cancer, colorectal cancer, and cholangiocarcinoma $(53,54)$. Akt-mediated Girdin phosphorylation in cancer-associated fibroblasts is closely related to the development of tumors, and inhibiting this function of Akt can cause a decrease in tumor progression (55). Radiotherapy (RT) is a powerful therapeutic method for cancer treatment, and inhibition of the Akt/cyclin D1 pathway can result in radiosensitization of both surviving tumor cells and cancer stem cells (56). The effects of PGRN on regulating Akt have been confirmed in several cancer types including colorectal, bladder, gastric, and cervical cancers (57-59). PGRN can stimulate the phosphoinositide 3-kinase/Akt/mammalian target of rapamycin pathway in cancer tissues and contributes to the carcinogenesis of cancer (58). In colorectal cancer, PGRN can promote proliferation and angiogenesis via the TNFR2/ Akt/ERK pathway (7). PGRN-dependent activation of Akt is related to the invasion, motility, and anchoragedependent growth of cancer (60).

\section{$M A P K$}

The effects of MAPK on proliferation, survival, differentiation, and migration have been reported in a number of cancers $(61,62)$. In addition, MAPK plays an important role in several cancers including mitochondrial dysfunction, oxidative stress, and endoplasmic reticulum stress (63-65). MAPK is critical for PGRN biological responses in cancer (66). PGRN contributes to the activation of MAPK by regulating drebrin and then induces $\mathrm{F}$-actin remodeling, thereby regulating growth, motility, and invasion of urothelial cancer cells. PGRN downregulation inhibits bladder cancer cell growth and sensitizes cancer cells to cisplatin, and MAPK plays a critical role in this process (67). Anti-PGRN monoclonal antibody can reduce tumor cell proliferation and tumor angiogenesis through suppression of p44/42 MAPK in hepatocellular carcinoma (HCC) (68).

\section{VEGF}

The VEGF family comprises a number of members, among which VEGF-A is the most potent angiogenic factor and vascular endothelial growth factor receptor 2 (VEFGR-2) is the most crucial receptor in cancer (69). High VEGF levels have been reported in several cancers (70). As an angiogenic growth factor, the prominent role of VEGF in cancer, specifically in stimulating angiogenesis, has been highlighted by many studies (71). A previous study confirmed that suppressing the expression of VEGF can promote cancer cell apoptosis and inhibit angiogenesis (72). Bevacizumab, an anti-VEGF targeting monoclonal antibody, can reduce vasculature density, and inhibit cancer progression and activation of several interrelated signaling pathways (73). PGRN reportedly has effects on promoting angiogenesis and metastasis through the regulation of VEGF in several cancers (74). In colorectal cancer cell lines, PGRN upregulation can promote the expression of Ki67 and VEGF-A as well as cancer growth rate, whereas PGRN downregulation has the opposite effects (7). In esophageal cancer, PGRN plays a significant role in promoting lymphangiogenesis by activating VEGF (75).

\section{Cyclin D1}

Cyclin D1 plays a pivotal role in cancer. Cyclin D1 
participates in promoting cell cycle progression in the G1 phase and has various biological activities in the process of tumorigenesis including promoting proliferation, enhancing DNA damage repair, and stimulating migration $(76,77)$. Meanwhile, suppression of cyclin D1 can inhibit the proliferation, invasion, and metastasis of cancer cells (78-80) and enhance chemosensitivity and radiosensitivity $(81,82)$. In addition, it has been demonstrated that cancer patients with high cyclin D1 levels have a worse prognosis and increased risk of mortality than those with low levels $(83,84)$. Several studies have demonstrated the effects of PGRN on the regulation of cyclin D1 levels in cancer. PGRN takes part in promoting the invasion and metastasis of squamous cell carcinoma through elevating the expression of cyclin D1 (85). Moreover, PGRN reportedly mediates mitogenic effects by stimulating cyclin D1 in cancer cells (86). PGRN short hairpin RNA, which can reduce cancer cell proliferation through cell cycle arrest at the G2/M stage and expression of cyclin D1, would be an effective approach for treating HCC (87). In ovarian cancer, the antisense PGRN vector inhibits the proliferation and invasion of highly malignant cancer cells, and partially reverses the malignant phenotype, which is related to downregulation of cyclin D1 and cyclin-dependent kinase $4(88,89)$.

\section{PGRN as a biomarker of cancer and a target for anti-cancer therapy}

Studies have reported that PGRN is overexpressed in a number of cancers such as ovarian, bladder, breast, lung, and cervical cancers (90-92); however, little PGRN expression has been detected in normal tissue (93). In addition, high levels of PGRN are associated with the higher malignancy of cancer and poor outcomes of cancer patients $(18,74,94)$. In non-small cell lung cancer, the serum expression of PGRN in stage IIIB/IV patients is much higher than that in stage lower patients (95). It also has been demonstrated that PGRN upregulation is closely correlated with the worse progression-free survival of patients with glioblastoma (96). Moreover, PGRN levels are important for predicting recurrence in cancer patients (97). Recurrence probability is much higher in breast cancer patients with higher PGRN serum levels (98). Therefore, PGRN is probably a significant diagnostic and prognostic biomarker for cancer. In addition, PGRN may be a potential target for cancer treatment because of its effects on the proliferation, angiogenesis, migration, and invasion of cancer. It has been confirmed that the downregulation of PGRN minimizes its effects on tumorigenesis (99). PGRN is a key factor for the tumorigenicity of breast cancer, as reducing PGRN levels can decrease proliferation and colony formation (100). In gastric cancer, inhibition of PGRN expression with small interfering RNA inhibits cancer cell migration (101). Inhibiting PGRN by antisense cDNA transfection can reduce proliferation and invasion in ovarian cancer (102). Suppression of PGRN expression by neutralizing antibody inhibits angiogenesis by decreasing VEGF expression and microvessel density (39). Furthermore, anti-PGRN antibody can sensitize the chemoresistant subpopulation generated by antineoplastic drugs and their parental cells to apoptosis $(67,103)$. Therefore, PGRN is not only a diagnostic and prognostic biomarker but also a potential target for cancer therapy.

\section{Future prospects of PGRN}

Cancer progression is a complex procedure involving many biological characteristics including proliferation, apoptosis, invasion, angiogenesis, and autophagy. Although the roles of PGRN in proliferation, apoptosis, invasion, and angiogenesis have been widely reported, the effect of PGRN on autophagy in cancer remains unclear. However, autophagy plays a significant role in cancer progression $(104,105)$. Autophagy induces the invasion and migration of cancer cells (106), and is a key factor in RT; thus, suppression of autophagy could decrease the clonogenic survival of cancer cells following irradiation $(107,108)$. In addition, there is a tight connection between apoptosis and autophagy, and the relationship is a hot point in cancer research. Autophagy is double-edged sword in different types of cancer cells, as it both induces and inhibits apoptosis $(109,110)$. Therefore, clarifying the effects and mechanisms of PGRN on autophagy in cancer is very essential for cancer treatment. In addition, RT is a powerful tool for the treatment of cancer and is widely used in cancer patients (111-113). However, radioresistance is a big problem $(114,115)$. Thus, effective measures to overcome radioresistance are urgently needed for cancer treatment. As there are no studies showing that PGRN has effects on RT, expounding the role of PGRN in RT is necessary.

\section{Conclusions}

An increasing number of studies have shown that PGRN is a key factor in cancer. In this review, we presented some of the important biological effects of PGRN in cancer as 
well as several molecular targets of PGRN involved in cancer progression. This evidence confirms that PGRN is a potential prognostic biomarker for cancer and an attractive therapeutic target for anti-cancer therapy. Current information regarding the role of PGRN in cancer is exciting, but future studies are warranted to elucidate the functions and signaling pathways of PGRN in cancer.

\section{Acknowledgments}

Thanks for the help of Medjaden Inc to modify this article. Funding: This study was supported by the grants from Ningbo Health Branding Subject Fund (PPXK2018-04), the Zhejiang Provincial Natural Science Foundation of China (LQ17H090002, LQ18H090002), and the Medicine and Health Science and Technology Projects of Zhejiang Province (2017KY588).

\section{Footnote}

Reporting Checklist: The authors have completed the Narrative Review reporting checklist. Available at https:// dx.doi.org/10.21037/tcr-20-2972

Peer Review File: Available at https://dx.doi.org/10.21037/ tcr-20-2972

Conflicts of Interest: All authors have completed the ICMJE uniform disclosure form (available at https://dx.doi. org/10.21037/tcr-20-2972). The authors have no conflicts of interest to declare.

Ethical Statement: The authors are accountable for all aspects of the work in ensuring that questions related to the accuracy or integrity of any part of the work are appropriately investigated and resolved.

Open Access Statement: This is an Open Access article distributed in accordance with the Creative Commons Attribution-NonCommercial-NoDerivs 4.0 International License (CC BY-NC-ND 4.0), which permits the noncommercial replication and distribution of the article with the strict proviso that no changes or edits are made and the original work is properly cited (including links to both the formal publication through the relevant DOI and the license). See: https://creativecommons.org/licenses/by-nc-nd/4.0/.

\section{References}

1. Jackman K, Kahles T, Lane D, et al. Progranulin deficiency promotes post-ischemic blood-brain barrier disruption. J Neurosci 2013;33:19579-89.

2. He Z, Bateman A. Progranulin (granulin-epithelin precursor, PC-cell-derived growth factor, acrogranin) mediates tissue repair and tumorigenesis. J Mol Med (Berl) 2003;81:600-12.

3. Bateman A, Bennett HP. The granulin gene family: from cancer to dementia. Bioessays 2009;31:1245-54.

4. Ghidoni R, Benussi L, Glionna M, et al. Low plasma progranulin levels predict progranulin mutations in frontotemporal lobar degeneration. Neurology 2008;71:1235-9.

5. Egashira Y, Suzuki Y, Azuma Y, et al. The growth factor progranulin attenuates neuronal injury induced by cerebral ischemia-reperfusion through the suppression of neutrophil recruitment. J Neuroinflammation 2013;10:105.

6. Göbel M, Eisele L, Möllmann M, et al. Progranulin is a novel independent predictor of disease progression and overall survival in chronic lymphocytic leukemia. PLoS One 2013;8:e72107.

7. Yang D, Wang LL, Dong TT, et al. Progranulin promotes colorectal cancer proliferation and angiogenesis through TNFR2/Akt and ERK signaling pathways. Am J Cancer Res 2015;5:3085-97.

8. Diaz-Cueto L, Arechavaleta-Velasco F, Diaz-Arizaga A, et al. PKC signaling is involved in the regulation of progranulin (acrogranin/PC-cell-derived growth factor/ granulin-epithelin precursor) protein expression in human ovarian cancer cell lines. Int J Gynecol Cancer 2012;22:945-50.

9. Monami G, Gonzalez EM, Hellman M, et al. Proepithelin promotes migration and invasion of 5637 bladder cancer cells through the activation of ERK1/2 and the formation of a paxillin/FAK/ERK complex. Cancer Res 2006;66:7103-10.

10. Atalay PB, Kuku G, Tuna BG. Effects of carbendazim and astaxanthin co-treatment on the proliferation of MCF-7 breast cancer cells. In Vitro Cell Dev Biol Anim 2019;55:113-9.

11. Arif M, Kitchen P, Conner MT, et al. Downregulation of aquaporin 3 inhibits cellular proliferation, migration and invasion in the MDA-MB-231 breast cancer cell line. 
Oncol Lett 2018;16:713-20.

12. Bishnupuri KS, Alvarado DM, Khouri AN, et al. IDO1 and Kynurenine Pathway Metabolites Activate PI3K-Akt Signaling in the Neoplastic Colon Epithelium to Promote Cancer Cell Proliferation and Inhibit Apoptosis. Cancer Res 2019;79:1138-50.

13. Zhou G, Yang J, Song P. Correlation of ERK/MAPK signaling pathway with proliferation and apoptosis of colon cancer cells. Oncol Lett 2019;17:2266-70.

14. Zhang M, Liu P, Xu F, et al. Vinculin promotes gastric cancer proliferation and migration and predicts poor prognosis in patients with gastric cancer. J Cell Biochem 2019;120:14107-15.

15. Sun MX, Yu F, Gong ML, et al. Effects of curcumin on the role of MMP-2 in endometrial cancer cell proliferation and invasion. Eur Rev Med Pharmacol Sci 2018;22:5033-41.

16. Tanimoto R, Morcavallo A, Terracciano M, et al. Sortilin regulates progranulin action in castration-resistant prostate cancer cells. Endocrinology 2015;156:58-70.

17. Cheung PFY, Cheung ST. Methods to Analyze the Role of Progranulin (PGRN/GEP) on Cancer Stem Cell Features. Methods Mol Biol 2018;1806:145-53.

18. Cuevas-Antonio R, Cancino C, Arechavaleta-Velasco F, et al. Expression of progranulin (Acrogranin/PCDGF/ Granulin-Epithelin Precursor) in benign and malignant ovarian tumors and activation of MAPK signaling in ovarian cancer cell line. Cancer Invest 2010;28:452-8.

19. Bandey I, Chiou SH, Huang AP, et al. Progranulin promotes Temozolomide resistance of glioblastoma by orchestrating DNA repair and tumor stemness. Oncogene 2015;34:1853-64.

20. Simpkins FA, Devoogdt NM, Rasool N, et al. The alarm anti-protease, secretory leukocyte protease inhibitor, is a proliferation and survival factor for ovarian cancer cells. Carcinogenesis 2008;29:466-72.

21. Fakai MI, Abd Malek SN, Karsani SA. Induction of apoptosis by chalepin through phosphatidylserine externalisations and DNA fragmentation in breast cancer cells (MCF7). Life Sci 2019;220:186-93.

22. Lui JC, Kong SK. Heat shock protein 70 inhibits the nuclear import of apoptosis-inducing factor to avoid DNA fragmentation in TF-1 cells during erythropoiesis. FEBS Lett 2007;581:109-17.

23. Kanno S, Hirano S, Sagi M, et al. Sulfide induces apoptosis and Rho kinase-dependent cell blebbing in Jurkat cells. Arch Toxicol 2013;87:1245-56.

24. Goldar S, Khaniani MS, Derakhshan SM, et al. Molecular mechanisms of apoptosis and roles in cancer development and treatment. Asian Pac J Cancer Prev 2015;16:2129-44.

25. Zhou X, Jiang W, Liu Z, et al. Virus Infection and Death Receptor-Mediated Apoptosis. Viruses 2017;9:316.

26. Ouyang L, Shi Z, Zhao S, et al. Programmed cell death pathways in cancer: a review of apoptosis, autophagy and programmed necrosis. Cell Prolif 2012;45:487-98.

27. Matsuura K, Canfield K, Feng W, et al. Metabolic Regulation of Apoptosis in Cancer. Int Rev Cell Mol Biol 2016;327:43-87.

28. Tanimoto R, Lu KG, Xu SQ, et al. Mechanisms of Progranulin Action and Regulation in Genitourinary Cancers. Front Endocrinol (Lausanne) 2016;7:100.

29. Daya M, Loilome W, Techasen A, et al. Progranulin modulates cholangiocarcinoma cell proliferation, apoptosis, and motility via the $\mathrm{PI} 3 \mathrm{~K} / \mathrm{pAkt}$ pathway. Onco Targets Ther 2018;11:395-408.

30. Kamrava M, Simpkins F, Alejandro E, et al. Lysophosphatidic acid and endothelin-induced proliferation of ovarian cancer cell lines is mitigated by neutralization of granulin-epithelin precursor (GEP), a prosurvival factor for ovarian cancer. Oncogene 2005;24:7084-93.

31. Duff D, Long A. Roles for RACK1 in cancer cell migration and invasion. Cell Signal 2017;35:250-5.

32. Wang X, Enomoto A, Asai N, et al. Collective invasion of cancer: Perspectives from pathology and development. Pathol Int 2016;66:183-92.

33. Zhou J, Cheng Y, Tang L, et al. Up-regulation of SERPINA3 correlates with high mortality of melanoma patients and increased migration and invasion of cancer cells. Oncotarget 2017;8:18712-25.

34. Xinzhou H, Ning Y, Ou W, et al. RKIp inhibits the migration and invasion of human prostate cancer PC-3M cells through regulation of extracellular matrix. Mol Biol (Mosk) 2011;45:1004-11.

35. Zhang Z, Che X, Yang N, et al. miR-135b-5p Promotes migration, invasion and EMT of pancreatic cancer cells by targeting NR3C2. Biomed Pharmacother 2017;96:1341-8.

36. Fan L, Wu Y, Wang J, et al. Sevoflurane inhibits the migration and invasion of colorectal cancer cells through regulating ERK/MMP-9 pathway by up-regulating miR203. Eur J Pharmacol 2019;850:43-52.

37. Swerlick RA. Angiogenesis. J Dermatol 1995;22:845-52.

38. Blood CH, Zetter BR. Tumor interactions with the vasculature: angiogenesis and tumor metastasis. Biochim Biophys Acta 1990;1032:89-118.

39. Huang H, Li J, Lu Y, et al. Role of midkine-progranulin interaction during angiogenesis of hepatocellular 
carcinoma. Int J Clin Exp Pathol 2015;8:8809-20.

40. Edwards JG, Cox G, Andi A, et al. Angiogenesis is an independent prognostic factor in malignant mesothelioma. Br J Cancer 2001;85:863-8.

41. Ferrara N. VEGF and the quest for tumour angiogenesis factors. Nat Rev Cancer 2002;2:795-803.

42. Welti J, Loges S, Dimmeler S, et al. Recent molecular discoveries in angiogenesis and antiangiogenic therapies in cancer. J Clin Invest 2013;123:3190-200.

43. Chen XY, Li JS, Liang QP, et al. Expression of PC cellderived growth factor and vascular endothelial growth factor in esophageal squamous cell carcinoma and their clinicopathologic significance. Chin Med J (Engl) 2008;121:881-6.

44. Tangkeangsirisin W, Serrero G. PC cell-derived growth factor (PCDGF/GP88, progranulin) stimulates migration, invasiveness and VEGF expression in breast cancer cells. Carcinogenesis 2004;25:1587-92.

45. Kim JH. Chemotherapy for colorectal cancer in the elderly. World J Gastroenterol 2015;21:5158-66.

46. Ku GY. Systemic therapy for esophageal cancer: chemotherapy. Chin Clin Oncol 2017;6:49.

47. Cai Q, Wang S, Jin L, et al. Long non-coding RNA GBCDRlnc1 induces chemoresistance of gallbladder cancer cells by activating autophagy. Mol Cancer 2019;18:82.

48. Hu Y, Feng FY, Chen SJ, et al. Correlation between the expression of PCDGF in serum and the chemotherapeutic sensitivity in NSCLC. Zhonghua Zhong Liu Za Zhi 2006;28:603-5.

49. Hu Y, Lin DM, Cheng SJ, et al. Influences of PC cellderived growth factor and breast cancer resistance protein on the curative effects of platinum-based chemotherapeutic regimens for advanced non-small cell lung cancer. Zhonghua Yi Xue Za Zhi 2006;86:2611-4.

50. Abrhale T, Brodie A, Sabnis G, et al. GP88 (PCCell Derived Growth Factor, progranulin) stimulates proliferation and confers letrozole resistance to aromatase overexpressing breast cancer cells. BMC Cancer 2011;11:231.

51. Tangkeangsirisin W, Hayashi J, Serrero G. PC cell-derived growth factor mediates tamoxifen resistance and promotes tumor growth of human breast cancer cells. Cancer Res 2004;64:1737-43

52. Lo HC, Hsu JH, Lai LC, et al. MicroRNA-107 enhances radiosensitivity by suppressing granulin in $\mathrm{PC}-3$ prostate cancer cells. Sci Rep 2020;10:14584.

53. Noorolyai S, Mokhtarzadeh A, Baghbani E, et al. The role of microRNAs involved in PI3-kinase signaling pathway in colorectal cancer. J Cell Physiol 2019;234:5664-73.

54. Labib PL, Goodchild G, Pereira SP. Molecular Pathogenesis of Cholangiocarcinoma. BMC Cancer 2019;19:185.

55. Yamamura Y, Asai N, Enomoto A, et al. Akt-Girdin signaling in cancer-associated fibroblasts contributes to tumor progression. Cancer Res 2015;75:813-23.

56. Shimura T. Targeting the AKT/cyclin D1 pathway to overcome intrinsic and acquired radioresistance of tumors for effective radiotherapy. Int J Radiat Biol 2017;93:381-5.

57. Yang D, Li R, Wang H, et al. Clinical implications of progranulin in gastric cancer and its regulation via a positive feedback loop involving AKT and ERK signaling pathways. Mol Med Rep 2017;16:9685-91.

58. Feng T, Zheng L, Liu F, et al. Growth factor progranulin promotes tumorigenesis of cervical cancer via PI3K/Akt/ mTOR signaling pathway. Oncotarget 2016;7:58381-95.

59. Wang L, Yang D, Tian J, et al. Tumor necrosis factor receptor 2/AKT and ERK signaling pathways contribute to the switch from fibroblasts to CAFs by progranulin in microenvironment of colorectal cancer. Oncotarget 2017;8:26323-33.

60. Xu SQ, Buraschi S, Morcavallo A, et al. A novel role for drebrin in regulating progranulin bioactivity in bladder cancer. Oncotarget 2015;6:10825-39.

61. Rezatabar S, Karimian A, Rameshknia V, et al. RAS/ MAPK signaling functions in oxidative stress, DNA damage response and cancer progression. J Cell Physiol 2019. [Epub ahead of print]. doi: 10.1002/jcp.28334.

62. Sheng $W$, Chen $C$, Dong $M$, et al. Calreticulin promotes EGF-induced EMT in pancreatic cancer cells via Integrin/ EGFR-ERK/MAPK signaling pathway. Cell Death Dis 2017;8:e3147.

63. Yan J, Feng Z, Liu J, et al. Enhanced autophagy plays a cardinal role in mitochondrial dysfunction in type 2 diabetic Goto-Kakizaki (GK) rats: ameliorating effects of (-)-epigallocatechin-3-gallate. J Nutr Biochem 2012;23:716-24.

64. Fan S, Qi M, Yu Y, et al. P53 activation plays a crucial role in silibinin induced ROS generation via PUMA and JNK. Free Radic Res 2012;46:310-9.

65. Younce CW, Kolattukudy PE. MCP-1 causes cardiomyoblast death via autophagy resulting from ER stress caused by oxidative stress generated by inducing a novel zinc-finger protein, MCPIP. Biochem J 2010;426:43-53.

66. Xu SQ, Buraschi S, Tanimoto R, et al. Analysis of 
Progranulin-Mediated Akt and MAPK Activation. Methods Mol Biol 2018;1806:121-30.

67. Buraschi S, Xu SQ, Stefanello M, et al. Suppression of progranulin expression inhibits bladder cancer growth and sensitizes cancer cells to cisplatin. Oncotarget 2016;7:39980-95.

68. Ho JC, Ip YC, Cheung ST, et al. Granulin-epithelin precursor as a therapeutic target for hepatocellular carcinoma. Hepatology 2008;47:1524-32.

69. Costache MI, Ioana M, Iordache S, et al. VEGF Expression in Pancreatic Cancer and Other Malignancies: A Review of the Literature. Rom J Intern Med 2015;53:199-208.

70. Frezzetti D, Gallo M, Maiello MR, et al. VEGF as a potential target in lung cancer. Expert Opin Ther Targets 2017;21:959-66.

71. Ahluwalia A, Jones MK, Matysiak-Budnik T, et al. VEGF and colon cancer growth beyond angiogenesis: does VEGF directly mediate colon cancer growth via a non-angiogenic mechanism? Curr Pharm Des 2014;20:1041-4.

72. Ren CC, Yang L, Liu L, et al. Effects of shRNA-mediated silencing of PSMA7 on cell proliferation and vascular endothelial growth factor expression via the ubiquitinproteasome pathway in cervical cancer. J Cell Physiol 2019;234:5851-62.

73. Mahdi A, Darvishi B, Majidzadeh-A K, et al. Challenges facing antiangiogenesis therapy: The significant role of hypoxia-inducible factor and MET in development of resistance to anti-vascular endothelial growth factortargeted therapies. J Cell Physiol 2019;234:5655-63.

74. Li LQ, Huang HL, Ping JL, et al. Clinicopathologic and prognostic implications of progranulin in breast carcinoma. Chin Med J (Engl) 2011;124:2045-50.

75. Li G, Dong T, Yang D, et al. Progranulin promotes lymphangiogenesis through VEGF-C and is an independent risk factor in human esophageal cancers. Hum Pathol 2018;75:116-24.

76. Casimiro MC, Di Sante G, Ju X, et al. Cyclin D1 Promotes Androgen-Dependent DNA Damage Repair in Prostate Cancer Cells. Cancer Res 2016;76:329-38.

77. Ramos-García P, Gil-Montoya JA, Scully C, et al. An update on the implications of cyclin D1 in oral carcinogenesis. Oral Dis 2017;23:897-912.

78. Yuan C, Zhu X, Han Y, et al. Elevated HOXA1 expression correlates with accelerated tumor cell proliferation and poor prognosis in gastric cancer partly via cyclin D1. J Exp Clin Cancer Res 2016;35:15.

79. Zhang Y, Su Y, Zhao Y, et al. MicroRNA-720 inhibits pancreatic cancer cell proliferation and invasion by directly targeting cyclin D1. Mol Med Rep 2017;16:9256-62.

80. Fusté NP, Fernández-Hernández R, Cemeli T, et al. Cytoplasmic cyclin D1 regulates cell invasion and metastasis through the phosphorylation of paxillin. Nat Commun 2016;7:11581.

81. Su H, Jin X, Shen L, et al. Inhibition of cyclin D1 enhances sensitivity to radiotherapy and reverses epithelial to mesenchymal transition for esophageal cancer cells. Tumour Biol 2016;37:5355-63.

82. Yang $\mathrm{P}$, Chen W, Li X, et al. Downregulation of cyclin D1 sensitizes cancer cells to MDM2 antagonist Nutlin-3. Oncotarget 2016;7:32652-63.

83. Lin JX, Xie XS, Weng XF, et al. Overexpression of IC53d promotes the proliferation of gastric cancer cells by activating the AKT/GSK3 $\beta /$ cyclin D1 signaling pathway. Oncol Rep 2019;41:2739-52.

84. Ahlin C, Lundgren C, Embretsén-Varro E, et al. High expression of cyclin D1 is associated to high proliferation rate and increased risk of mortality in women with ERpositive but not in ER-negative breast cancers. Breast Cancer Res Treat 2017;164:667-78.

85. Huang K, Huang C, Shan K, et al. Significance of PC cell-derived growth factor and cyclin D1 expression in cutaneous squamous cell carcinoma. Clin Exp Dermatol 2012;37:411-7.

86. Lu R, Serrero G. Mediation of estrogen mitogenic effect in human breast cancer MCF-7 cells by PC-cell-derived growth factor (PCDGF/granulin precursor). Proc Natl Acad Sci U S A 2001;98:142-7.

87. Park MY, Park YS, Nam JH. RNA interference against granulin-epithelin precursor prevents hepatocellular carcinoma growth: its application as a therapeutic agent. Int J Oncol 2011;39:853-61.

88. Liu YL, Wang Y, Lang Y, et al. Inhibitory effects of an antisense PCDGF vector on proliferation and invasion of highly malignant ovarian cancer cells and the related mechanism. Zhonghua Zhong Liu Za Zhi 2009;31:90-4.

89. Liu Y, Xi L, Liao G, et al. Inhibition of PC cell-derived growth factor (PCDGF)/granulin-epithelin precursor (GEP) decreased cell proliferation and invasion through downregulation of cyclin D and CDK4 and inactivation of MMP-2. BMC Cancer 2007;7:22.

90. Wei Z, Huang Y, Xie N, et al. Elevated expression of secreted autocrine growth factor progranulin increases cervical cancer growth. Cell Biochem Biophys 2015;71:189-93.

91. Carlson AM, Maurer MJ, Goergen KM, et al. Utility of 
progranulin and serum leukocyte protease inhibitor as diagnostic and prognostic biomarkers in ovarian cancer. Cancer Epidemiol Biomarkers Prev 2013;22:1730-5.

92. Li LQ, Min LS, Jiang Q, et al. Progranulin expression in breast cancer with different intrinsic subtypes. Pathol Res Pract 2012;208:210-6.

93. Tkaczuk KR, Yue B, Zhan M, et al. Increased Circulating Level of the Survival Factor GP88 (Progranulin) in the Serum of Breast Cancer Patients When Compared to Healthy Subjects. Breast Cancer (Auckl) 2011;5:155-62.

94. Yamamoto Y, Goto N, Takemura M, et al. Association between increased serum GP88 (progranulin) concentrations and prognosis in patients with malignant lymphomas. Clin Chim Acta 2017;473:139-46.

95. Edelman MJ, Feliciano J, Yue B, et al. GP88 (progranulin): a novel tissue and circulating biomarker for non-small cell lung carcinoma. Hum Pathol 2014;45:1893-9.

96. Wang M, Li G, Yin J, et al. Progranulin overexpression predicts overall survival in patients with glioblastoma. Med Oncol 2012;29:2423-31.

97. Serrero G, Hawkins DM, Yue B, et al. Progranulin (GP88) tumor tissue expression is associated with increased risk of recurrence in breast cancer patients diagnosed with estrogen receptor positive invasive ductal carcinoma. Breast Cancer Res 2012;14:R26.

98. Koo DH, Park CY, Lee ES, et al. Progranulin as a prognostic biomarker for breast cancer recurrence in patients who had hormone receptor-positive tumors: a cohort study. PLoS One 2012;7:e39880.

99. Lu Y, Zheng L, Zhang W, et al. Growth factor progranulin contributes to cervical cancer cell proliferation and transformation in vivo and in vitro. Gynecol Oncol 2014;134:364-71.

100.Lu R, Serrero G. Inhibition of PC cell-derived growth factor (PCDGF, epithelin/granulin precursor) expression by antisense PCDGF cDNA transfection inhibits tumorigenicity of the human breast carcinoma cell line MDA-MB-468. Proc Natl Acad Sci U S A 2000;97:3993-8.

101. Wang H, Sun Y, Liu S, et al. Upregulation of progranulin by Helicobacter pylori in human gastric epithelial cells via $\mathrm{p} 38 \mathrm{MAPK}$ and MEK1/2 signaling pathway: role in epithelial cell proliferation and migration. FEMS Immunol Med Microbiol 2011;63:82-92.

102.Dong T, Yang D, Li R, et al. PGRN promotes migration and invasion of epithelial ovarian cancer cells through an epithelial mesenchymal transition program and the activation of cancer associated fibroblasts. Exp Mol Pathol 2016;100:17-25.

103. Wong NC, Cheung PF, Yip CW, et al. Antibody against granulin-epithelin precursor sensitizes hepatocellular carcinoma to chemotherapeutic agents. Mol Cancer Ther 2014;13:3001-12.

104. White E. The role for autophagy in cancer. J Clin Invest 2015;125:42-6.

105.Levy JMM, Towers CG, Thorburn A. Targeting autophagy in cancer. Nat Rev Cancer 2017;17:528-42.

106. Mowers EE, Sharifi MN, Macleod KF. Autophagy in cancer metastasis. Oncogene 2017;36:1619-30.

107. Tam SY, Wu VW, Law HK. Influence of autophagy on the efficacy of radiotherapy. Radiat Oncol 2017;12:57.

108. Apel A, Herr I, Schwarz H, et al. Blocked autophagy sensitizes resistant carcinoma cells to radiation therapy. Cancer Res 2008;68:1485-94.

109.Zhang L, Wang H, Zhu J, et al. Mollugin induces tumor cell apoptosis and autophagy via the PI3K/AKT/mTOR/ p70S6K and ERK signaling pathways. Biochem Biophys Res Commun 2014;450:247-54.

110.Zhang L, Wang H, Xu J, et al. Inhibition of cathepsin S induces autophagy and apoptosis in human glioblastoma cell lines through ROS-mediated PI3K/AKT/mTOR/ p70S6K and JNK signaling pathways. Toxicol Lett 2014;228:248-59.

111. Hennequin C, Barillot I, Azria D, et al. Radiotherapy of breast cancer. Cancer Radiother 2016;20 Suppl:S139-46.

112. Allen C, Her S, Jaffray DA. Radiotherapy for Cancer: Present and Future. Adv Drug Deliv Rev 2017;109:1-2.

113. de Perrot M, Wu L, Wu M, et al. Radiotherapy for the treatment of malignant pleural mesothelioma. Lancet Oncol 2017;18:e532-42.

114.Xie B, Zhang L, Hu W, et al. Dual blockage of STAT3 and ERK1/2 eliminates radioresistant GBM cells. Redox Biol 2019;24:101189.

115. Yong Y, Zhang C, Gu Z, et al. Polyoxometalate-Based Radiosensitization Platform for Treating Hypoxic Tumors by Attenuating Radioresistance and Enhancing Radiation Response. ACS Nano 2017;11:7164-76.

Cite this article as: Zhou C, Huang Y, Wu J, Wei Y, Chen $\mathrm{X}$, Lin Z, Nie S. A narrative review of multiple mechanisms of progranulin in cancer: a potential target for anti-cancer therapy. Transl Cancer Res 2021;10(9):4207-4216. doi: 10.21037/tcr-20-2972 